\title{
Pengaruh Pengetahuan dan Motivasi lbu Rumah Tangga Tentang Gerakan Masyarakat Hidup Sehat (GERMAS) di Kelurahan Talang Bakung Kota Jambi
}

\author{
Nurfitriani ${ }^{1}$, Ersa Anggraini ${ }^{2}$ \\ 1,2Sekolah Tinggi IImu Kesehatan Baiturrahim Jambi \\ Correspondence email: nurfitriani_1173@yahoo.com
}

\begin{abstract}
Abstrak. Gaya hidup dan perilaku yang tidak sehat dapat menyebabkan masalah kesehatan seperti hipertensi, stroke dan penyakit jantung koroner. Hal inilah yang melatarbelakangi pemerintah mencanangkan Gerakan Masyarakat Hidup Sehat (Germas) yang menitikberatkan untuk melakukan aktifitas fisik, konsumsi sayur dan buah, serta cek kesehatan secara berkala. Tujuan penelitian ini untuk mengetahui pengaruh pendidikan kesehatan terhadap pengetahuan dan motivasi ibu rumah tangga tentang Gerakan Masyarakat Hidup Sehat (GERMAS) dalam upaya pencegahan hipertensi di Kelurahan Talang Bakung Tahun 2018. Penelitian ini merupakan penelitian kuantitatif dengan pre Eksperiment pre test dan post test design dengan satu kelompok intervensi saja. Populasi penelitian ini sebanyak 2.210 KK, dengan jumlah sampel 20 IRT berusia antara 21-59 tahun dengan teknik purposive sampling. Penelitian ini dilaksanakan pada bulan Agustus 2018 di kelurahan Talang Bakung Jambi, Penelitian ini menggunakan kuesioner, dianalisis secara uji paired t-test. Hasil penelitian menunjukkan nilai rata rata pengetahuan sebelum diberikan pendidikan kesehatan (pre test) 4,3 dansetelah penkes (post test) menjadi 7,6. Nilai rata rata motivasi sebelum penkes (pre test ) 23,55 dan setelah penkes menjadi 29,05. Ada pengaruh yang bermakna terhadap pengetahuan dan motivasi ibu rumah tangga tentang Gerakan Masyarakat Hidup Sehat( Germas) dalam upaya pencegahan hipertensi dengan p-value 0,000. Diharapkan peran dari petugas kesehatan dan kader terus ditingkatkan lagi dalam memberikan konseling, informasi dan edukasi (KIE) baik dalam bentuk leafleat, poster ataupun dengan penyuluhan secara langsung pada ibu rumah tangga sekitar wilayah binaanya dengan meng ikuti kegiatan kemasyarakatan seperti arisan, pengajian dan lain lain sehingga pengetahuan dan motivasi ibu rumah tangga dapat meningkat dan sadar pentingnya menjaga pola hidup sehat dengan cara melakukan kegiatan Gerakan Masyarakat Hidup sehat secara teratur.
\end{abstract}

Kata Kunci: germas; hipertensi; motivasi; pendidikan kesehatan; pengetahuan

Abstract. Lifesty and unhealthy behavior can cause health problems such as hypertension, stroke and coronary heart disease. This is the background of the government launching the Movement for Healthy Living Society (Germas) which focuses on doing physical activities, consumption of vegetables and fruit, and regular health checks. The purpose of this study was to determine the effect of housewife knowledge about the Healthy Living Ccomunity Movement (GERMAS) in the prevention hypertension in Talang Bakung sub-district year 2018. This research was a quantitative descriptive study with only. pre-test and post-test design experiment test design with one group intervention only. The population of 2,210 KK, with total sample as 20 IRT, age 21-59 years using purposive sampling technique. This research was carried out in August 2018 in Talang Bakung sub-District. study used a questionnaire, analyzed by paired t-test. The results showed the value of average knowledge before a given health education (pre test) dansetelah penkes 4.3 (post test) to 7.6. The value of average motivation before penkes (pre test) 23.55 and after penkes be 29.05. There is asignificant effect towards the knowledge and motivation of housewives about healthy living Society Movement (Germas) in hypertension prevention efforts with a p-value of 0.000 . Expected role of health workers and cadres constantly improved again in providing counselling, information and education (KIE) in the form of a poster, or with leafleat outreach directly at housewives around the region binaanya with civic activities follow such as meng arisan, recitation and others so that the knowledge and motivation of housewives can be increased and conscious of the importance of maintaining healthy life patterns by living healthy Communities movement activities on a regular basis.

Keywords: germas; hypertension; motivation; health education; knowledge

\section{PENDAHULUAN}

Kesehatan sebagai hak asasi manusia dan salah satu unsur kesejahteraan menjadi tanggung jawab setiap orang. Pembangunan kesehatan ditujukan untuk meningkatkan kesadaran, kemauan dan kemampuan hidup sehat bagi setiap orang agar terwujudnya derajat kesehatan masyarakat setinggi-tingginya sebagai investasi pembangunan sumber daya manusia yang produktif secara sosial dan ekonomis. Peran serta masyarakat dan keluarga sangat diperlukan dalam memajukan kesehatan (Prasetyawati, 2011).

Salah satu upayameningkatkan derajat kesehatan masyarakat melalui pendidikan kesehatan sebagai bentuk intervensi terhadap salah satu faktor yang mempengaruhi derajat kesehatan.yaitu perilaku. Pendidikan kesehatan mrupakan bagian dari program pembangunan kesehatan yang ditujukan untuk pemberdayaan individu, keluarga dan masyarakat agar tumbuh perilaku hidup sehat yang bersumber pada masyarakat (Prasetyowati,2011). Hasil penelitian Triyanto, Iskanndar dan Saryono(2012), menggambarkan bahwa pendidikan kesehatan berengaruh terhadap pilihan dan perubahan perilaku.

Pembangunan kesehatan masyarakat pada hakekatnya adalah upaya yang dilaksanakan oleh semua komponen Bangsa Indonesia. Tujuannya untuk meningkatkan kesadaran dan kemampuan hidup sehat bagi setiap orang agar terwujud derajat kesehatan masyarakat yang setinggi-tingginya (Kemenkes RI, 2017).

Kemenkes RI (2017) melaporkan bahwa saat ini Indonesia tengah mengalami perubahan pola penyakit yang disebut transisi epidemiologi yang ditandai dengan meningkatnya kematian dan kesakitan akibat penyakit tidak menular (PTM) seperti, stroke, jantung, diabetes, dan lain-lain. Meningkatnya kejadian PTM berdampak pada meningkatnya pembiayaan pelayanan kesehatan yang harus ditanggung oleh masyarakat dan 
pemerintah. Selain itu menurunnya produktivitas masyarakat, menurunnya daya saing negara, dan pada akhirnya mempengaruhi kondisi sosial ekonomi masyarakat itu sendiri. Data menunjukkan bahwa periode 1990-2015, kematian akibat PTM meningkat dari $37 \%$ menjadi $57 \%$. Di sisi lain, kematian akibat penyakit menular menurun dari $56 \%$ menjadi $38 \%$.

Menurut Indrati dan Gardjito (2014), pada tahun 2007 pengeluaran masyarakat dunia untuk kesehatan adalah $10 \%$ karena kecelakaan, $40 \%$ karena penyakit infeksi, dan 50\% karena penyakit degeneratif yang terkait erat dengan pola makan dan pola hidup sehat. Biaya kesehatan masyarakat untuk penyakit degeneratif di Indonesia senilai 11,6 triliun rupiah. Dari data tersebut, penyakit degeneratif yang terkait erat dengan pola hidup sehat merupakan ancaman terbesar bagi masyarakat. Gaya hidup masyarakat yang beresiko terhadap penyakit degeneratif yaitu antara lain merokok, makanan tidak sehat, dan kurangnya kegiatan fisik (olahraga). Ketiga faktor gaya hidup tersebut berpotensi menimbulkan penyakit antara lain, penyakit kardiovaskuler, diabetes mellitus, kanker, dan obesitas. Prevalensi penyakit akibat gaya hidup tidak sehat ini terus mengalami peningkatan dari tahun ke tahun.

Gaya hidup dan perilaku yang tidak sehat dapat menyebabkan masalah kesehatan seperti hipertensi. Ketika hipertensi telah diidentifikasi, pengetahuan mengenai penyakit dan penatalaksanaannya sangat diperlukan bagi pasien tersebut. Keinginan untuk bertanggung jawab terhadap penatalaksanaan hipertensi adalah hal pokok agar dapat mengontrol tekanan darah efektif dengan mengadopsi perubahan gaya hidup sehat (LeMone dkk, 2016). Pada tahun 2003, penyakit kardiovaskuler merupakan penyebab kematian utama di Indonesia. Penyakit ini, antara lain hipertensi, stroke dan penyakit jantung koroner (PJK). Penderita diabetes memiliki risiko yang lebih besar untuk mengalami penyakit kardiovaskuler. Prevalensi penyakit kardiovaskuler ini terus mengalami peningkatan setiap tahun, seiring dengan semakin meningkatnya jumlah penderita diabetes. (Indrati \& Gardjito, 2014).

Menurut National Heart Lung and Blood Institute tahun 2004, Hipertensi adalah isu kesehatan masyarakat yang penting. Saat hipertensi jarang menyebabkan gejala atau keterbatasan nyata pada kesehatan fungsional pasien, Hipertensi adalah faktor risiko utama pada penyakit jantung koroner, gagal jantung dan stroke. World Health Organization (WHO) mengidentifikasi tekanan darah diatas tingkat normal (TD sistolik > $115 \mathrm{mmHg}$ ) sebagai penyebab $62 \%$ penyakit serebrovaskuler dan $49 \%$ penyakit jantung iskemik diseluruh dunia (Lamone dkk,2016).

Hasil penelitian Dr. Kenneth H. Cooper (1994) yang berjudul Antioxidant Revolution menunjukkan bahwa aktivitas olahraga ringan pun sudah cukup bermanfaat untuk mencegah penyakit jantung coroner sekaligus mencegah stroke ( Handoko, 2011). Berdasarkan Riset Kesehatan Dasar (Riskesdas) tahun 2013, ada sejumlah faktor risiko perilaku kesehatan yang terjadi, yakni penduduk kurang aktivitas fisik sebanyak $(26,1 \%)$, perilaku merokok sejak usia dini
$(36,3 \%)$, penduduk umur $>10$ tahun kurang konsumsi buah dan sayur $(93,5 \%)$, penduduk $>10$ tahun minumminuman beralkohol (4,6\%). Seperti diketahui saat ini, pola makan buruk, asupan gizi tidak seimbang, kurang aktivitas fisik, kebiasaan merokok, dan lain-lain, telah melekat pada sebagian besar keseharian masyarakat kita (Kemenkes RI, 2017).

Menurut Kemenkes RI (2017), situasi inilah yang melatarbelakangi pemerintah melahirkan Gerakan Masyarakat Hidup Sehat (GERMAS). Gerakan ini didasari oleh Instruksi Presiden Nomor 1 Tahun 2017 yang memerintahkan kepada seluruh kementerian/lembaga dan pemerintah daerah untuk membuat kebijakan dan melakukan tindakan untuk membangun kesadaran, kemauan dan kemampuan berperilaku sehat masyarakat untuk meningkatkan kualitas hidupnya. Saat ini GERMAS difokuskan pada himbauan masyarakat melakukan aktivitas fisik, mengkonsumsi sayur dan buah, dan memeriksakan kesehatan secara berkala. Melalui GERMAS, diharapkan agar kerjasama antar sektor dan lintas program menjadi katalisator bagi masyarakat untuk mampu berperilaku hidup sehat, yang pada akhirnya dapat membentuk sumber daya manusia Indonesia yang unggul sehingga menjadi pondasi bangsa Indonesia yang kuat. Dalam kehidupan sehari-hari, menerapkan pola hidup yang sehat merupakan salah satu wujud dari revolusi mental. Melalui GERMAS, pemerintah khususnya Kemenkes mengajak masyarakat untuk mengubah kebiasaan-kebiasaan yang tidak sehat, menjadi mau melakukan langkah kecil perubahan pola hidup ke arah yang lebih sehat.

Berdasarkan data dari Dinas Kesehatan Kota Jambi didapatkan bahwa penyakit hipertensi merupakan penyakit tidak menular terbesar yang diderita oleh masyarakat di Kota Jambi tahun 2017, diikuti oleh penyakit Diabetes Mellitus pada urutan kedua dan obesitas pada urutan ketiga. Hal ini juga diperkuat oleh data kunjungan pasien hipertensi yang berkunjung di 20 Puskesmas Kota Jambi Berdasarkan data dari Dinas Kesehatan Kota Jambi pada tahun 2016-2017 jumlah kunjungan penderita hipertensi pada Puskesmas Talang Bakung pada Tahun 2016 dengan jumlah kunjungan penderita hipertensi 2.505 dan pada tahun 2017 terjadi peningkatan hingga 750 dari jumlah tahun sebelumnya menjadi jumlah kunjungan penderita hipertensi 3.255.

Berdasarkan survei awal yang dilakukan peneliti pada tanggal 29 sampai 30 Juni 2018 terhadap 10 orang ibu rumah tangga di Kelurahan Talang Bakung dengan metode wawancara didapatkan hasil bahwa 6 dari 10 orang tersebut mengatakan bahwa belum tahu apa itu Gerakan Masyarakat Hidup Sehat, kemudian mengatakan sangat jarang melakukan aktivitas fisik, biasanya hanya sekedar melakukan pekerjaan rumah seperti mencuci, menyapu dan lainnya, dan tidak mengetahui manfaat dari aktivitas fisik, kemudian jarang mengkonsumsi buah-buahan di karenakan harga buah yang cukup mahal.

Ibu Rumah Tangga tersebut mengatakan jarang mengkonsumsi sayur di karenakan lebih menyukai makanan seperti siao saji di bandingkan sayuran, dan jarang mengecek tekanan darah karena alasan malas ke pelayanan kesehatan, belum mengetahui apa saja 
upaya yang dapat dilakukan untuk menjaga kestabilan tekanan darah agar terhindar dari hipertensi. 3 orang lainnya mengatakan sudah tahu tentang Gerakan Masyarakat namun belum rutin melakukan kegiatan Germas, mereka mengatakan berolahraga namun tidak rutin. 1 orang berikutnya mengatakan sama sekali tidak mengetahui Gerakan Masyarakat Hidup Sehat, kemudian mengatakan sangat jarang sekali berolahraga bahkan tidak mengetahui pentingnya melakukan aktivitas fisik seperti olahraga dan peregangan otot lainnya, jarang memperhatikan kesehatannya seperti tidak mau mengkonsumsi sayur dan buahan dengan alasan tidak suka sayuran dan harga buah yang cukup mahal, serta sangat jarang ke pelayanan kesehatan untuk memeriksa kesehatannya.

Berdasarkan permasalahan diatas dapat disimpulkan masih banyak masyarakat Indonesia khususnya masyarakat Jambi di Kelurahan Talang Bakung belum mengetahui gerakan masyarakat Hidup Sehat ( Germas) yang dicanangkan oleh pemerintah sebagai upaya meningkatkan derajat kesehatan masyarakat khususnya mengatasi penyakit Hipertensi

Tujuan penelitian ini diketahuinyai pengaruh pendidikan kesehatan tentang Germas terhadap pengetahuan dan motivasi Ibu Rumah Tangga dalam upaya pencegahan Hipertensi di Kelurahan Talang Bakung Jambi.

\section{METODE PENELITIAN}

Penelitian ini merupakan penelitian kuantitatif dengan menggunakan desain Pre Eksperiment pre test dan post test, dimana hanya ada kelompok intervensi ( perlakuan ) saja yang bertujuan untuk mengetahui pengaruh pendidikan kesehata $\mathrm{n}$ tentang Germas terhadap pengetahuan dan motivasi ibu rumah tangga dalam upaya pencegahan Hipertensi. Peneliti melakukan observasi sebanyak $2 x$ yaitu sebelum (pre test) dan sesudah (post test) pemberian pendidikan kesehatan yang, dilaksanakan pada bulan Agustus 2018 di Kelurahan Talang Bakung Jambi. Populasi penelitian sebanyak $2.210 \mathrm{KK}$, dengan tehnik pengambilan sampel secara Purposive Sampling sebanyak 20 ibu rumah tangga berusia antara 21-59 tahun yang tidak menderita hipertensi dan bertempat tinggal diKel. Talang Bakung dan bersedia menjadi responden. Instrumen pengetahuan ada 12 pernyataan berkaitan kegiatan Germas yang terdiri dari pernyataan positif dan negatif. Ada 7 pernyataan positif dan pernyataan negatif ada 5. Skala pengukuran jawaban menggunakan skala Guttman dimana pernyataan berupa benar dan salah, jika pada pernyataan positif menjawab benar maka diberi nilai 1 dan jika menjawab salah diberi nilai 0 . Pernyataan negatif jika dijawab benar diberi nilai 1 dan jika salah diberi nilai 0 .

Pernyataan motivasi terdiri dari 10 pernyataan, dimana terdiri dari 7 pernyataan positif dan 3 pernyataan negatif. Skala jawaban menggunakan pengukuran skala Likert dimana Jika pada pertanyaan positif responden mejawab pernyataan sangat setuju maka diberi nilai 4 , setuju diberi nilai 3 , tidak setuju diberi nilai 2 dan sangat tidak setuju diberi nilai 1 . Jika pada pertanyaan negatif responden menjawab pertanyaan sangat setuju diberi nilai 1 , setuju diberi nilai 2 , tidak setuju diberi nilai 3 dan sangat tidak setuju diberi nilai 4 .

Pengumpulan data dengan cara pengisian kuisioner yang dibagikan sebelum dan sesudah pemberian pendidikan kesehatan tentang Germas sebagai pencegahan Hipertensi. Analisa data yang digunakan, yaitu analisis univariat dan analisi bivariat dengan uji paired t-test.

\section{HASIL DAN PEMBAHASAN Analisis Univariat Gambaran Pengetahuan Sebelum dan Sesudah Kesehatan \\ Ibu Rumah Tangga Dilakukan Pendidikan}

Pengetahuan tentang Germas adalah sesuatu yang diketahui ibu rumah tangga tentang kegiatan Germas meliputi aktifitas fisik, makan sayur dan buah serta pemeriksaan kesehatan secara rutin. Berdasarkan hasil pengukuran skor pengetahuan ibu rumah tangga sebelum dan sesudah diberikan pendidikan kesehatan dapat dilihat dalam tabel 1 berikut :

Tabel 1. Skor Pengetahuan Ibu Rumah Tangga Sebelum \& Sesudah Dilakukan Pendidian Kesehatan Tentang Germas Dalam Upaya Pencegahan Hipertensi

\begin{tabular}{cccc}
\hline No & $\begin{array}{c}\text { Skor } \\
\text { Pengetahuan } \\
\text { Pre Test }\end{array}$ & $\begin{array}{c}\text { Skor } \\
\text { Pengetahuan } \\
\text { Post Test }\end{array}$ & Selisih \\
\hline $\mathbf{1}$ & 4 & 6 & 2 \\
$\mathbf{2}$ & 5 & 9 & 4 \\
$\mathbf{3}$ & 4 & 8 & 4 \\
$\mathbf{4}$ & 2 & 5 & 3 \\
$\mathbf{5}$ & 6 & 10 & 4 \\
$\mathbf{6}$ & 4 & 9 & 5 \\
$\mathbf{7}$ & 2 & 5 & 3 \\
$\mathbf{8}$ & 4 & 7 & 3 \\
$\mathbf{9}$ & 6 & 8 & 2 \\
$\mathbf{1 0}$ & 6 & 9 & 3 \\
$\mathbf{1 1}$ & 5 & 10 & 5 \\
$\mathbf{1 2}$ & 4 & 6 & 2 \\
$\mathbf{1 3}$ & 4 & 8 & 4 \\
$\mathbf{1 4}$ & 3 & 5 & 2 \\
$\mathbf{1 5}$ & 5 & 9 & 4 \\
$\mathbf{1 6}$ & 5 & 8 & 3 \\
$\mathbf{1 7}$ & 4 & 7 & 3 \\
$\mathbf{1 8}$ & 4 & 6 & 2 \\
$\mathbf{1 9}$ & 5 & 8 & 3 \\
$\mathbf{2 0}$ & 4 & 9 & 5 \\
Jumlah & 86 & 152 & 66 \\
Rata-rata & 4,3 & 7,6 & 3,3 \\
\hline
\end{tabular}

Berdasarkan tabel 1 diatas diketahui bahwa distribusi frekuensi rata-rata pengetahuan ibu rumah tangga tentang Germas dalam upaya pencegahan hipertensi sebelum dilakukan pendidikan kesehatan dengan nilai mean 4.3 dan sesudah dilakukan pendidikan kesehatan nilai mean adalah 7,6 dimana terjadinya peningkatan pengetahuan antara Pre Test dan Post Test. Skor terendah ibu rumah tangga sebelum dilakukan pendidikan kesehatan adalah 2 dan skor tertinggi adalah 6 , hal ini dikarenakan mereka belum mendapat informasi mengenai Germas sehingga mereka hanya mengisi kuisioner berdasarkan apa yang mereka ketahui. Sedangkan setelah diberikan pendidikan kesehatan skor terendah ibu rumah tangga 
adalah 5 dan skor tertinggi adalah 10, dikarenakan ibu rumah tangga telah mendapatkan pendidikan kesehatan dari peneliti dan banyaknya responden yang antusias pada saat peneliti melakukan penyuluhan dan didukung juga dengan ibu membawa pulang leafleat sehingga pada saat pengukuran post test, pengetahuan ibu rumah tangga menjadi bertambah. .

Dari hasil penelitian diperoleh bahwa pengetahuan ibu mengalami peningkatan dikarenakan ada dukungan dari karakteristik ibu seperti pendidikan yang rata rata berpendidikan SMA sebanyak $45 \%$.

Pendidikan kesehatan didefinisikan sebagai usaha atau kegiatan untuk membantu individu, kelompok atau masyarakat dalam meningkatkan kemampuan perilaku mereka untuk mencapai tingkat kesehatannya secara optimal. Pendidikan kesehatan merupakan proses belajar pada individu, kelompok atau masyarakat dari tidak tahu tentang nilai-nilai kesehatan menjadi tahu, dari tidak mampu mengatasi masalahmasalah kesehatannya sendiri menjadi mampu.(Notoatmodjo,2011).

Pengetahuan adalah merupakan hasil "tahu", dan ini terjadi setelah orang melakukan pengindraan terhadap suatu obyek tertentu. Pengetahuan atau kognitif merupakan domain yang sangat penting untuk terbentuknya tindakan seseorang (Wawan dan Dewi, 2010).

\section{Gambaran Motivasi lbu Rumah Tangga Tentang Germasi Sebelum Dan Sesudah Diberikan Pendidikan Kesehatan}

Dorongan dari dalam individu ibu rumah tangga untuk bertindak atau berprilaku dalam mencegah hipertensi dengan melalui Germas. Berdasarkan hasil penelitian skor motivasi ibu rumah tangga dapat dilihat pad tabel berikut:

Tabel 2. Skor Motivasi Ibu Rumah Tangga Sebelum \& Sesudah Dilakukan Pendidikan Kesehatan Tentang Germas Dalam Upaya Pencegahan Hipertensi

\begin{tabular}{cccc}
\hline No & $\begin{array}{c}\text { Skor } \\
\text { Motivasi Pre } \\
\text { Test }\end{array}$ & $\begin{array}{c}\text { Skor Motivasi } \\
\text { Post Test }\end{array}$ & Selisih \\
\hline $\mathbf{1}$ & 23 & 27 & 4 \\
$\mathbf{2}$ & 23 & 26 & 3 \\
$\mathbf{3}$ & 25 & 31 & 6 \\
$\mathbf{4}$ & 24 & 31 & 7 \\
$\mathbf{5}$ & 25 & 24 & -1 \\
$\mathbf{6}$ & 26 & 30 & 4 \\
$\mathbf{7}$ & 22 & 29 & 7 \\
$\mathbf{8}$ & 20 & 26 & 6 \\
$\mathbf{9}$ & 24 & 24 & 0 \\
$\mathbf{1 0}$ & 25 & 31 & 6 \\
$\mathbf{1 1}$ & 23 & 30 & 7 \\
$\mathbf{1 2}$ & 22 & 31 & 9
\end{tabular}

\begin{tabular}{cccc}
$\mathbf{1 3}$ & 22 & 29 & 7 \\
$\mathbf{1 4}$ & 23 & 32 & 9 \\
$\mathbf{1 5}$ & 24 & 28 & 4 \\
$\mathbf{1 6}$ & 24 & 28 & 4 \\
$\mathbf{1 7}$ & 24 & 33 & 9 \\
$\mathbf{1 8}$ & 24 & 29 & 5 \\
$\mathbf{1 9}$ & 26 & 33 & 7 \\
$\mathbf{2 0}$ & 22 & 29 & 7 \\
Jumlah & 471 & 581 & 110 \\
Rata - Rata & 23,55 & 29,05 & 5,5 \\
\hline
\end{tabular}

Berdasarkan Tabel 2 memperlihatkan skor ratarata motivasi ibu rumah tangga tentang Germas dalam upaya pencegahan hipertensi sebelum (pre test) dilakukan pendidikan kesehatan sebesar 23,55 dan sesudah (post tes) dilakukan pendidikan kesehatan dengan nilai 29,05 dimana terjadinya peningkatan motivasi antara pre test dan post test. Nilai motivasi terendah ibu rumah tangga sebelum dilakukan pendidikan kesehatan adalah 20 dan nilai tertinggi adalah 26, sedangkan setelah dilakukan pendidikan kesehatan nilai motivasi terendah ibu rumah tangga adalah 24 dan nilai tertinggi adalah 33, hal ini dikarenakan setiap orang memiliki motivasi intrinsik yang berbeda beda dalam melakukan suatu hal.

Menurut Lestari (2015), Motivasi adalah karakteristik psikologis manusia yang memberikan kontribusi pada tingkat komitmen seseorang. Motivasi juga merupakan kekuatan, dorongan, kebutuhan, tekanan, dan mekanisme psikologis yang dimaksudkan sebagai akumulasi faktor-faktor internal dan eksternal.

Peningkatan motivasi melalui pemberian pendidikan kesehatan pada dasarnya memang sesuai dengan hasil penelitian ini, dimana dapat dilihat dari peningkatan nilai mean motivasi sebelum dan sesudah dilakukan pendidikan kesehatan. Penerimaan informasi setiap orang berbeda beda karena dipengaruhi oleh faktor umur, pendidikan, dan pengalaman seseorang (Notoatmodjo (2011). Jika dilihat dari karakteristik responden yang diteliti berdasarkan umur ibu rumah tangga terbanyak masuk dalam kategori umur 46-55 tahun (55\%) dan pendidikan terbanyak SMA (45\%).

\section{Analisis Bivariat}

Hasil bivariat digunakan untuk mengetahui pengaruh pendidikan kesehatan terhadap pengetahuan dan motivasi ibu rumah tangga dalam upaya pencegahan Hipertensi yang dianalisis menggunakan paired sampel t-test dengan hasil sebagai berikut:

\section{Pengaruh Pendidikan Kesehatan Terhadap Pengetahuan Ibu Rumah Tangga Tentang Germas dalam Upaya Pencegahan Hipertensi di Kelurahan Talang Bakung tahun 2018.}

Tabel 3. Pengaruh Pendidikan Kesehatan Terhadap Pengetahuan Ibu Rumah Tangga Tentang Germas dalam Upaya Pencegahan Hipertensi di Kelurahan Talang Bakung tahun 2018

\begin{tabular}{cccccc}
\hline Variabel & Mean & SD & SE & Selisih Mean & P-Value \\
\hline Pengetahuan sebelum penkes (pre test) & 4,30 & 1,129 & 0,252 & $-3,30$ & 0,000 \\
Pengetahuan setelah penkes (post test) & 7,60 & 1,635 & 0,366 & & 20 \\
\hline
\end{tabular}

Tabel 3 menunjukkan bahwa hasil penelitian yang diperoleh dari 20 ibu rumah tangga dengan pengetahuan ibu rumah tangga tentang Germas dalam upaya pencegahan hipertensi di Kelurahan Talang Bakung Tahun 2018, diketahui rata-rata tingkat pengetahuan ibu rumah tangga sebelum dilakukan 
pendidikan kesehatan (pre test) 4,30 dengan standar deviasi 1,129, sedangkan pengetahuan setelah pendidikan kesehatan (post test) adalah 7,60 dengan standar deviasi 1,635 , dengan selisih nilai mean $-3,30$. Berdasarkan hasil uji statistic didapatkan nilai $p$-value $=$ $0,000$ ( $p<0,05)$ dari hasil penelitian tersebut menunjukkan bahwa terdapat pengaruh pendidikan kesehatan tentang Germas dalam upaya pencegahan hipertensi.

Hasil penelitian ini hampir sama dengan penelitian yang dilakukan oleh Susanti (2012) tentang "Pengaruh Pendidikan Kesehatan Tentang Hipertensi Terhadap Pengetahuan Dan Sikap Mengelola Hipertensi Di Puskesmas Pandanaran Semarang", dengan hasil variabel pengetahuan sebelum dan sesudah diberikan pendidikan kesehatan $0,000(p<0,05)$, kemudian untuk variabel sikap adalah $0,000(p<0,05)$. Ini menunjukkan bahwa ada pengaruh yang signifikan antara pemberian pendidikan kesehatan dan sikap baik sebelum dan sesudah diberikan pendidikan kesehatan tentang hipertensi. Kesimpulan dari penelitian ini adalah pendidikan kesehatan tentang hipertensi mempengaruhi pengetahuan dan sikap dalam mengelola hipertensi.

Selama penyuluhan berlangsung ibu rumah tangga mendapat informasi dan penjelasan terkait dengan materi penyuluhan dalam upaya pencegahan hipertensi melalui Germas.selain itu juga para ibu ibu membawa leafleat yang dibagikan kerumah agar dapat dipelajariataupun dibaca anggota keluarga lainnya, sehingga ketika diberikan kuisioner yang sama dengan sebelum penyuluhan, terdapat perubahan yang bermakna .

Dari penjelasan diatas menurut peneliti bahwa tejadinya peningkatan pengetahuan ibu rumah tangga tentang Germas dalam upaya pencegahan hipertensi idak terlepas peran dari petugas kesehatan dan kader dalam memberikan penyuluhan dan kegiatan lainnya. Menurut peneliti agar kegiatan Germas ini dapat dimaksimalkan lagi dengan memberikan leafleat, memasang poster Germas, meng upayakan mengaktifkan lagi kegiatan posbindu ataupun dengan pendekatan kegiatan pengajian, arisan ataupun secara berkelompok.

\section{Pengaruh Pendidikan Kesehatan Terhadap Motivasi Ibu Rumah Tangga Tentang Germas dalam Upaya Pencegahan Hipertensi di Kelurahan Talang Bakung tahun 2018.}

Tabel 4 .Pengaruh Pendidikan Kesehatan Terhadap Motivasi Ibu Rumah Tangga Tentang Germas dalam Upaya Pencegahan Hipertensi di Kelurahan Talang Bakung tahun 2018

\begin{tabular}{|c|c|c|c|c|c|c|}
\hline Variabel & Mean & SD & SE & Selisih Mean & p-value & $\mathrm{n}$ \\
\hline Motivasi sebelum penkes (Pre Test) & 23,55 & 1,504 & 0,336 & -5.500 & 0,000 & 20 \\
\hline Motivasi setelah penkes (Postest) & 29,05 & 2,645 & 0,591 & & & \\
\hline
\end{tabular}

Tabel 4 menunjukkan bahwa hasil penelitian yang diperoleh tentang motivasi 20 ibu rumah tangga tentang Germas dalam upaya pencegahan hipertensi di Kelurahan Talang Bakung Tahun 2018, diketahui ratarata tingkat motivasi responden sebelum dilakukan pendidikan kesehatan (pre test) 23,55 dengan standar deviasi 1,504 sedangkan motivasi setelah pendidikan kesehatan (post test) dilakukan pendidikan kesehatan adalah 29,05 dengan standar deviasi 2,645, dan selisih nilai mean $-5,500$. Berdasarkan hasil uji statistic didapatkan nialai $p$-value $=0,000(p<0,05)$, dapat disimpulkan ada pengaruh yang bermakna tentang Germas terhadap pengetahuan dan motivasi ibu rumah tangga dalam upaya pencegahan hipertensi.

Menurut Triyanto (2014) Tahap primer penatalaksanaan penyakit hipertensi merupakan upaya awal pencegahan sebelum seseorang menderita hipertensi melalui program penyuluhan dan pengendalian faktor-faktor risiko kepada masyarakat luas dengan memprioritaskan pada kelompok resiko tinggi. Pendidikan kesehatan dan promosi kesehatan merupakan strategi utama dalam pencegahan tahap primer. Tujuan pendidikan kesehatan dan promosi kesehatan dimaksudkan untuk perubahan perilaku seseorang dalam mencegah terjadinya kesakitan. Upaya primer yang dimaksudkan sebagai pencegahan hipertensi dengan cara merubah faktor risiko antara lain : a)pola makan yang baik;b) perubahan gaya hidup seperti olahraga teratur, menghentikan merokok, membatasi konsumsi alkohol dan mengurangi berat badan.
Penelitian ini juga sejalan dengan Karso dan Wibawa (2017) tentang "Research On Government Programs Healthy Living community Movement'( GERMAS) in Bali Using Critical Discourse analysis dimana hasil penelitiannya The result show that government efforts to improve public health in Bali will be well received. The community considers the government's movement to adopt a healthy lifestyle in accordance with the religion of most Balinese people. In addition, considering the impact of non-infectious disease (PTM) which is socio economically very detrimental to society will certainly get good reception for the community.

Sesuai dengan program pemerintah (2017) yaitu Gerakan Masyarakat Hidup Sehat dimana pemerintah mengajak masyarakat untuk berpola hidup sehat seperti melakukan aktivitas fisik, makan buah dan sayur, pemeriksaan kesehatan secara berkala, membersihkan lingkungan, tidak merokok, tidak minum alkohol dan menggunakan jamban sehat.

Peningkatan motivasi melalui pemberian promosi kesehatan ini pada dasarnya memang sesuai dengan hasil ini, dimana promosi kesehatan berpengaruh terhadap peningkatan motivasi yang dapat dilihat dari perbedaan nilai mean yang ada. Akan tetapi masih terdapat beberapa responden yang tidak mengalami peningkatan motivasi atau mempunyai tingkat motivasi yang sama. Hal tersebut dikarenakan penerimaan informasi pada setiap orang itu berbeda. Penerimaan informasi sebagai motivasi menurut Notoatmodjo (2011) 
dapat dipengaruhi oleh faktor umur, pendidikan, dan pengalaman yang pernah diperoleh.

Menurut peneliti bahwa terjadinya peningkatan motivasi ibu rumah tangga tentang germas dalam upaya pencegahan hipertensi tidak terlepas dari peran petugas kesehatan dalam memberikan penddikan kesehatan secara langsung maupun dengan menggunakan media seperti leafleat, lembar balik dan lain lain. Selain itu juga motivasi dapat diperoleh dari dalam diri individu itu sendiri setelah mengetahui banyak manfaatnya.

Gerakan Masyarakat Hidup Sehat (Germas) merupakan suatu tindakan yang sistematis dan terencana yang dilakukan secara bersama-sama oleh seluruh komponen bangsa dengan kesadaran, kemauan dan kemampuan berperilaku sehat untuk meningkatkan kualitas hidup. GERMAS dapat dilakukan dengan cara: melakukan aktifitas fisik, mengkonsumsi sayur dan buah, tidak merokok, tidak mengkonsumsi alkohol, memeriksa kesehatan secara rutin, membersihkan lingkungan, dan menggunakan jamban. Pada tahap awal, GERMAS secara nasional dimulai dengan berfokus pada tiga kegiatan, yaitu: melakukan aktivitas fisik 30 menit per hari, mengkonsumsi buah dan sayur; dan memeriksakan kesehatan secara rutin (Kemenkes $\mathrm{RI}, 2017$ ).

Sebenarnya pengetahuan dan motivasi dapat dipengaruhi dari pendidikan kesehatan. Terjadinya peningkatan pengetahuan dan motivasi ibu rumah setelah dilakukannya pendidikan kesehatan ini dipengaruhi antara lain dari latar belakang umur ibu rumah tangga yang rata -rata 46-55 tahun (55\%), dengan tingkat pendidikan terbnayak SMA (45\%) dan juga mendapatkan informasi dari perawat atau petugas kesehatan yang memberikan penyuluhan dan konseling secara langsung, juga melalui media cetak dan elektronik. Maka diperlukannya peran dari petugas kesehatan untuk memberikan konseling, informasi dan edukasi (KIE) kepada ibu rumah tangga agar dapat mengetahui tentang Germas dalam upaya pencegahan hipertensi dan memotivasi ibu rumah tangga untuk berpola hidup sehat dengan melakukan kegiatan Germas seperti : 1) melakukan aktifitas fisik, 2) makan buah dan sayur, serta 3) memeriksakan kesehatan secara berkala untuk mencegah terjadinya peningkatan tekanan darah sehingga tekanan darah selalu dalam batas normal.

Menurut Kemenkes (2017) tujuan dari Germas itu sendiri adalah : 1). Intervensi gizi 1000 hari pertama kehidupan 2)Memperbaiki pola konsumsi gizi seimbang seluruh keluarga 3). Meningkatkan aktifitas fisik teratur dan terukur 4). Meningkatkan pola hidup sehat 5). Meningkatkan lingkungan sehat 6). Mengurangi konsumsi rokok dan alkohol. Untuk mengatasi masih kurangnya kesadaran dan kemauan dan motivasi masyarakat untuk berpola hidup sehat maka dilakukan penyuluhan kesehatan yang dilakukan oleh petugas kesehatan.

Dari hasil penelitian terlihat perbedaan sebelum dan sesudah dilakukan pendidikan kesehatan terhadap pengetahuan dan motivasi ibu rumah tangga tentang Germas dalam upaya pencegahan hipertensi mengalami peningkatan pengetahuan dan motivasi. Hasil penelitian diatas menunjukkan bahwa pendidikan kesehatan tentang Germas dalam upaya pencegahan hipertensi terbukti efektif bermanfaat dan berpengaruh dalam peningkatan pengetahuan dan motivasi ibu rumah tangga sehingga ibu rumah tangga mau melakukan kegiatan Germas agar terhindar dari penyakit hipertensi.

Pendidikan kesehatan didefinisikan sebagai usaha atau kegiatan untuk membantu individu, kelompok atau masyarakat dalam meningkatkan kemampuan perilaku mereka untuk mencapai tingkat kesehatannya secara optimal. Pendidikan kesehatan itu juga proses belajar pada individu, kelompok atau masyarakat dari tidak tahu tentang nilai-nilai kesehatan menjadi tahu, dari tidak mampu mengatasi masalahmasalah kesehatannya sendiri menjadi mampu. (Notoatmodjo,2011).

Salah satu upaya peningkatan pengetahuan Ibu Rumah Tangga untuk mencegah hipertensi adalah dengan diberikannya pendidikan kesehatan. Hal ini sejalan dengan Teori Mubarak (2007) yaitu Tujuan utama dalam memberikan pendidikan kesehatan yaitu merubah pengetahuan, sikap dan perilaku seseorang.

Pengetahuan adalah merupakan hasil "tahu", dan ini terjadi setelah orang melakukan pengindraan terhadap suatu obyek tertentu. Pengetahuan atau kognitif merupakan domain yang sangat penting untuk terbentuknya tindakan seseorang (overt behaviour) (Wawan dan Dewi, 2010).

\section{SIMPULAN}

a. Skor rata rata dari pengetahuan pre test adalah 4,30 dan setelah pemberian pendidikan kesehatan (post test) menjadi 7.60, dengan selisih mean $-3,30$.

b. Skor rata rata dari motivasi (pre test) adalah 23,55 dan setelah pemberian pendidikan kesehatan (post test) menjadi 29,05 dengan selisih mean -5,500.

c. Ada pengaruh yang bermakna terhadap pengetahuan dan motivasi ibu rumah tangga tentang Germas dalam upaya pencegahan hipertensi di Kelurahan Talang Bakung dengan nilai $p$-value $=$ 0,000 .

\section{DAFTAR PUSTAKA}

Darmawan D \& Siti Zulfa. 2015 . Pengaruh Promosi Kesehatan Terhadap Motivasi Pasien Hiprtensi Tentang Pelaksanaan Diet Hipertensi di poliklinik Penyakit dalam RS Rajawali Bandung.

http://ejournal.upi.edu/index.php/JPKI/announcement diakses tanggal 27 Agustus 2018.

Dinas Kesehatan Kota Jambi. 2017. Profil Kesehatan Jambi. Jambi.

Handoko Haryo Agus. 2011. Rahasia Awet Muda dan Panjang Umur

Indrati Retno \& Murdijati Gardjito. 2014. Pendidikan Konsumsi Pangan. Jakarta : Kencana Prenadamedia Group.

Irianto Koes . 2014 . Ilmu Kesehatan Masyarakat . Bandung. : Alfabeta

Karso Olih S dan Wibawa Arya Pageh, . 2017. Reseach On Government Programs"Healthy Living Community Movement (GERMAS) In BaliUsing Critical Discourse Analysis. International Journal of Research-GRANTHAALYAH5(6):82. ISSN2350-0530 (O, ISSn-2394-3629 
https://zenodo.org/record/815873\#.XWVz4N4zbM $\underline{w}$

Kemenkes RI. 2017. Buku Panduan Gerakan Masyarakat Hidup Sehat (GERMAS). Jakarta.

Lestari Titik. 2015. Kumpulan Teori Untuk Kajian Pustaka Penelitian Kesehatan. Yogyakarta : Nuha Medika

Notoatmodjo. 2011. IImu Kesehatan Masyarakat IImu dan Seni. Rineka Cipta : Jakarta

Prasyetyawati Arsita Eka . 2014 . Ilmu Kesehatan Masyrakat. Yogyakarta : Nuha Medika.

Puskesmas Talang Bakung. 2018. Data tentang seluruh Penderita Hipertensi yang berkunjung ke Puskesmas Talang Bakung Kota Jambi tahun anggaran 2018. Jambi

Susanti Tri Mega, 2012 . Pengaruh Pendidikan Kesehatan Tentang Hipertensi

TerhadapPengetahuan Dan Sikap Mengelola Hipertensi Di Puskesmas Pandanaran Semarang. http://ejournal.stikestelogorejo.ac.id/index.php/ilm ukeperawatan/article/view/66

Triyanto, Endang. 2014. Pelayanan Keperawatan Bagi Penderita Hipertensi Secara Terpadu. Yogyakarta : Graha IImu

Wawan, A dan Dewi, M. 2010. Teori dan Pengukuran Pengetahuan, Sikap dan Perilaku Manusia. Yogyakarta : Nuha Medika. 